\title{
Juicio previo como condición constitucional impeditiva del dictado de una condena en las instancias recursivas
}

\section{POR GABRIEL HERNÁN DI GIULIO(*)}

\begin{abstract}
Sumario: I. Introducción.- II. El término proceso.- III. La exigencia constitucional de juicio previo: primera condición para penar.- IV. La exigencia convencional de doble conforme: segunda condición para penar.- V. Comparación entre la primera y la segunda condición. VI. Coherencia entre la primera y la segunda condición.- VII. Estándares de la Corte IDH respecto de la segunda condición. VIII. Cuestiones no abordadas: la nulidad de la sentencia absolutoria y reenvío.- IX. Conclusiones.- X. Bibliografía.
\end{abstract}

Resumen: el juicio previo como exigencia constitucional (artículo 18, Constitución Nacional Argentina) no se reduce a la verificación de un proceso penal llevado en forma legal. El adjetivo "previo" señala que la sentencia condenatoria debe ser el consecuente directo del juicio. Se trata de la primera condición esencial de la garantía del debido proceso. La segunda condición encuentra su fuente en el Derecho Internacional de los Derechos Humanos (artículos 8.2.h de la Convención Americana de Derechos Humanosy 14.5 del Pacto Internacional de Derechos Civiles y Políticos) y se conoce como doble conforme o doble instancia. Ambas condiciones se desenvuelven en forma coherente y armónica con la siguiente implicancia: no se puede condenar en la fase recursiva, revocando el fallo absolutorio, sin infringir la garantía del debido proceso.

(*) Doctor en Derecho. Magister en Derecho Procesal. Esp. en Magistratura. Prof. Titular de Derecho Procesal, Facultad de Derecho, Universidad Nacional del Centro de la provincia de Buenos Aires (UNICEN). Investigador categoría III del Programa de Incentivos a Docente Investigadores del Ministerio de Educación de la Nación. Investigador del IEJUS. 
Palabras clave: juicio - previo - recurso - sentencia - absolutoria

\title{
The trial, as a previous process, is a constitutional impediment to pronounce an appellate court sentence
}

\begin{abstract}
: the trial, as a previous process, is a constitutional requirement (art. 18, Argentine National Constitution) and it is not limited to the verification of a legal process. The adjective "previous" states that the conviction must be the direct consequence of the trial. This is the first essential condition for ensuring due process of law. The second condition finds its source in International Human Rights Law (arts. 8.2.h of the American Convention on Human Rights and 14.5 of the International Covenant on Civil and Political Rights) and is referred to as double jeopardy. Both conditions develop in a coherent and harmonious way with the following implication: It's not allowed to condemn in the recursive phase, overturning the acquittal, without violating the guarantee of the due process.
\end{abstract}

Keywords: trial - previous - appeal - sentence - acquitting

\section{Introducción}

La garantía del debido proceso se integra con principios, reglas y condiciones que la constituyen. Así, por ejemplo, la imparcialidad e independencia del tribunal, la bilateralidad y contradicción en las instancias (o sustanciación de las acusaciones) que constituyen la idea de debate dialéctico, constituyen buenos ejemplos.

El debido proceso, como concepto innominado pero conglobante de aquellos principios, reglas y condiciones, encuentra su fuente en la Constitución Nacional y en el Derecho Internacional de los Derechos Humanos. Este último ordenamiento dispone estándares mínimos que los Estados deben observar para la protección de los seres humanos.

El marco múltiple exige su integración y aplicación armónica y coherente. Pero ese lineamiento, de carácter epistemológico tanto como político, coexiste con dos derivaciones del ámbito de aplicabilidad. A saber: 1) los estándares del Derecho Internacional de los Derechos Humanos constituyen una medida mínima o elemental que los Estados deben cumplir, y por consiguiente esa medida puede superarse mediante previsiones de derecho interno que proyecten mayor protección; 2) los estándares, valores, deberes de los Estados y los derechos de los seres humanos en los casos calificados como delitos de lesa humanidad, crímenes de guerra y graves violaciones de los derechos humanos(1) conforman categorías

(1) En otro trabajo que integra la bibliografía (Di Giulio, 2019, pp. 862-866), sostengo - y procuro demostrar- que los crímenes sexuales contra niñas constituyen graves violaciones de los derechos 
independientes, que incidirán necesaria y particularmente en la composición material de la garantía del debido proceso; de modo que estas categorías no puede ser asimiladas a la investigación y juzgamiento de delitos comunes. En este estudio no se analizan las especiales condiciones que aquellas categorías contienen, en especial en lo referente a la composición de garantía del debido proceso y los derechos de las víctimas. Por consiguiente, las conclusiones no pueden hacerse extensivas a los casos alcanzados por tales clases.

Despejadas las principales cuestiones que podrían conducir a confusión, se aprecia que la temática alcanzada como derivación del alcance de la garantía del debido proceso a partir de la condición impuesta por el juicio previo es, en definitiva, la potestad recursiva del Ministerio Público Fiscal o del querellante o particular damnificado frente a una sentencia absolutoria.

Esta última problemática ha sido materia de un significativo número de trabajos y se ha volcado en criterios disidentes en la Corte Suprema de Justicia. Existen agudos estudios que la abordan a la luz del principio ne bis in idem (Maier, 2015, pp. 299-318), del principio de inmediación - pero en su acepción no restringida, entendida como base del juicio oral y público- (Rovatti, 2016, pp. 129-130; Maier, 2004, pp. 17-18) y del principio de publicidad en los juicios penales. Con mucha elocuencia, Rovatti aborda el problema de las "condenas sin juicio" (p. 130).

Mi trabajo aborda la problemática aportando una perspectiva que se cimenta en el carácter previo del juicio como exigencia constitucional para penar. Por ende, introduce algunas razones que convergen o apoyan las conclusiones que señalan la imposibilidad de condenar en los estadios recursivos.

\section{El término proceso}

El proceso pertenece al género procedimiento (Alvarado Velloso, 2015, pp. 167-170), pero no debe ser confundido con este. Desde su dimensión ontológica constituye un método de debate para la resolución de conflictos o la imposición de penas. Es un método lógico y consecuencial porque representa fases o etapas ideales que le son inherentes. La Corte Suprema ha reconocido estos estadios como componentes estructurales de la garantía del debido proceso. En el proceso penal se los ha identificado como ACUSACIÓN- DEFENSA- PRUEBA y SENTENCIA.

El carácter consecuencial responde a tres factores inherentes: a) la temporalidad; b) la causalidad; y c) la direccionalidad.

humanos y, por consiguiente, corresponde aplicar los estándares propios de su categorización, de acuerdo con el Derecho Internacional de los Derechos Humanos. 


\section{a) La temporalidad}

El proceso se desenvuelve en el tiempo. $\mathrm{Y}$ aun cuando el tiempo alcanza a todos los fenómenos de la interacción humana, y por esta razón podría considerarse una perogrullada, no es ese alcance lo que factoriza el fenómeno sino su desenvolvimiento. El proceso es dinámico, se desenvuelve. Desenvolverse en mucho más que permanecer. Es potencia y realización. Potencia de aquello que puede acaecer - o que puede ser-y realización de lo que se concreta efectivamente. El desarrollo temporal implica su construcción. De modo que en el proceso se aprecia con facilidad los estadios temporales: el pasado, el presente y el futuro. Su proyección como potencia y realización lo sujeta a criterios de razonabilidad cronológica, al punto que puede ser descalificado por su prolongación más allá de lo razonable.

\section{b) La causalidad}

Sus etapas se vinculan lógicamente, estructuradas como antecedente y consecuente. La estructura esencial o genética del proceso no puede ser invertida o alterada sin infringir la idea de proceso.

La acusación es el antecedente de la defensa y esta su consecuencia. La prueba es el consecuente de la acusación y la defensa. Y así ocurre sucesivamente.

\section{c) La direccionalidad}

La progresión causal de las fases del proceso se dirige hacia su objeto, que es la sentencia. Esto indica que existe un sentido único que se explica con "ir hacia", la flecha del tiempo (Massuh, 1990). El norte es la consecución del objeto.

La dirección también se explica desde otras perspectivas. Todo proceso se origina a partir de afirmaciones (que podrán denominarse litigios, acusación, requerimiento de elevación a juicio, etc.). Las afirmaciones son relatos acerca de la ocurrencia de hechos típicamente antijurídicos, con la pretensión de que se adjudiquen consecuencias disvaliosas a quien se atribuye su comisión: la pena. La cuestión radica en que todos los procesos se originan con relatos acerca de la existencia de hechos constitutivos (conflictos o delitos) y esos relatos no deben (ni pueden) considerarse "ciertos" o "verdaderos" per se. Y más allá del estado de inocencia, connatural con el garantismo y el Estado de Derecho, los relatos son alcanzados por la incertidumbre. Desde la dimensión epistemológica(2) el problema de incertidumbre es connatural con la idea de proceso. Su superación se procura

(2) Lejos estoy, con esta expresión, de pretender una epistemología del proceso. 
con el dictado de una sentencia. La dirección se promueve desde la incertidumbre hacia certeza (la primera como realidad, la segunda como potencia).

La Corte Suprema de la Nación Argentina en el memorable precedente "Mattei" (Fallos: 272: 188) señaló que el proceso penal se integra por una serie de etapas en forma "progresiva", con las que se tiende a poner al juez en condiciones de dictar veredicto de absolución o de condena. Cada una de las etapas constituye el presupuesto necesario de las siguientes, destacando: “(...) el principio de la progresividad impide que el juicio se retrotraiga a etapas ya superadas, porque también debe considerarse axiomático que los actos procesales se precluyen cuando han sido cumplidos observando las formas que la ley establece, es decir, salvo supuesto de nulidad" (Fallos: 272: 188).

Con un claro ejemplo del principio pro homine sostuvo también:

(...) los valores que entran en juego en el juicio penal, obedecen al imperativo de satisfacer una exigencia consustancial con el respecto debido a la dignidad del hombre, cual es el reconocimiento del derecho que tiene toda persona a liberarse del estado de sospecha que importa la acusación de haber cometido un delito, mediante una sentencia que establezca, de una vez y para siempre, su situación frente a la ley penal (Fallos: 272: 188).

La Corte Nacional identificó las cualidades del juicio penal basadas en la "progresión" (aunque amparada más en la garantía de inviolabilidad de la defensa en juicio), "preclusión" (cuyo límite se reconoce en las nulidades por cuestiones esenciales), "seguridad jurídica y justicia razonablemente rápida" (la primera como valor y la segunda como pauta o criterio de valoración -y posible invalidación-).

\section{La exigencia constitucional de juicio previo: primera condición para penar}

Desde su sanción en 1853, la Constitución Nacional (CN) prohíbe penar sin juicio previo (artículo 18). La expresión es específica porque condiciona solo a una de las dos alternativas regularmente posibles en una sentencia definitiva. Y esa selección se explica porque para nuestra carta magna la relación entre Estado e individuo se cimenta en la libertad como principio y los márgenes de su ejercicio se encuentran en los principios de reserva y legalidad (artículos 1, 14, 19, 28, 31 y cctes. CN). De modo que la exigencia de "juicio previo" es una condición ineludible para que se pueda penar, y no lisa y llanamente para que se pronuncie una sentencia cualquiera sea su contenido. Vale decir que, para la previsión constitucional, no es la absolución la hipótesis que sujeta la condición sino la imposición 
de pena (Rovatti, 2016, pp. 130-136; Maier, 2015, pp. 299-318). Penar presupone, indefectiblemente, el dictado de una condena.

Me detendré en el adjetivo previo. La expresión reconoce como su antecedente inmediato el Proyecto de Constitución para la Confederación Argentina de Juan Bautista Alberdi. En su artículo número 19 contenía una expresión equivalente, pero con la utilización de la palabra "condenado" en lugar del término "penado" que acompaña el texto constitucional.

Como lo reseña cuidadosamente Zarini (1993, pp. 127-134), el Estatuto Provisional para la dirección y administración del Estado del 5 de mayo de 1815 (artículo IV), el Estatuto Provisional del 22 de noviembre de 1816 (Secc. 7, artículo 4), el Reglamento Provisorio del 3 de diciembre de 1817 (Secc. VII, artículo IV), la Constitución de 1819 (Secc. V, artículo CXVIII) y la Constitución de 1826 (artículo 171) contenían disposiciones equivalentes que predicaban que ningún habitante podía ser penado sin que preceda juicio y sentencia legal.

El Proyecto de Constitución de Pedro de Angelis contenía una propuesta sensiblemente diferente (artículo 123) mediante la fórmula que prohíbe el dictado de una condena "sin haber sido juzgado legalmente" (Zarini, 1993).

La expresión constitucional se compone de dos palabras: un sustantivo, "juicio", y un adjetivo, "previo".

La palabra "juicio" refiere técnicamente al proceso. En el sistema acusatorio, en el que se inscribe sin hesitación nuestra Constitución Nacional, el proceso se define como un método de debate, como tal ungido de las reglas de contradicción y bilateralidad, en el que las partes (acusador y acusado) ejercen sus pretensiones y defensas frente a un tercero imparcial (juez, tribunal o jurado) que debe reunir los requisitos que impone la garantía de juez natural. La defensa de la persona y de los derechos es inviolable y esta garantía, aunque es conceptualmente independiente, se encuentra íntimamente ligada con el desenvolvimiento y concreción del debido proceso.

El proceso como debate dialéctico debe ser distinguido de otras fases procedimentales, como la investigación que no es dialéctica, ni puede asimilarse al debate. El procedimiento es el género, constituido por toda serie de actos consecuenciales, mientras que el proceso es la especie que conforma la serie de actos consecuenciales en una estructura dialéctica, sometida a la resolución de un tercero imparcial, entre litigantes a quienes se reconoce el ejercicio de la defensa de sus intereses y derechos, en plano de igualdad procesal (Alvarado Velloso, 2015, pp. 167-170) principio que, en ocasiones, requiere la instauración de asimetrías para su materialización. 
En el juicio se observa la inveterada estructura que nuestro máximo Tribunal de Justicia extrajo de la garantía del debido proceso, constituida por ACUSACIÓN, DEFENSA, PRUEBA y SENTENCIA (CSJN, Fallos: 272:188).

El uso del adjetivo "previo" señala que la palabra "juicio" por sí misma no abastece la condición exigible para penar. En primer lugar, porque gramaticalmente la frase juicio previo no equivale, ni puede ser reducida, a la palabra juicio. El uso del adjetivo tiene una implicancia inocultable como cualidad o accidente, como calificante o determinante del sustantivo. Se reconoce en el adjetivo su aptitud para modificar al sustantivo o denotar, como función propia, sus propiedades o relaciones. En segundo lugar, porque no es posible interpretar (o al menos no podría ser ese el primer parámetro hermenéutico) que el constituyente ha adjetivado la palabra juicio sin intención de denotar una propiedad o relación del sustantivo. Estaríamos señalando, en ese caso, que el constituyente habría incurrido en una formulación tautológica.

Previo significa "anticipado, que va delante o que sucede primero" (diccionario de la Real Academia Española). El concepto que encierra la palabra juicio presupone su ubicuidad en comparación con el acto decisional (sentencia), desde que el juicio es anterior a la sentencia. Sin embargo, como ya se expuso, no se puede considerar que el constituyente ha incurrido en redundancia, empleando un adjetivo que nada aporta al significado del sustantivo. Por el contrario, "previo" indica una cercanía, una relación consecuencial inmediata, en el sentido de inmediatamente anterior o antecedente de. El juicio es previo al acto de penar, que es una consecuencia posible. Pero la consecuencia es inherente a un antecedente necesario, imperativo. Ese antecedente necesario sustenta constitucionalmente el estado de inocencia.

El juicio previo es una condición para penar, que implica que una condena debe ser su directa e inmediata derivación o resultante. Por razones expositivas volveré sobre el punto al tratar la garantía de la doble instancia (infra 6), para mostrar que la condición no se cumple si el juicio y la condena no reconocen una relación consecuencial, directa e inmediata.

El juicio previo es la primera condición de la garantía del debido proceso. Surge de la Constitución Nacional Argentina y no se limita a la exigencia de juicio o proceso legal.

La constitución nacional, además de imponer la primera condición, se integró con las siguientes previsiones: 
1) Sujetó programáticamente al modelo de juicio por jurados el juzgamiento de delitos comunes, en el ámbito de las competencias locales (artículos 5, 7, 24, 67 inc. 12, 102, 104, 105, CN).

2) Dispuso que los procedimientos y las autoridades judiciales resultarían de las leyes provinciales o federales, según la materia.

3) Erigió al Poder Judicial de la Nación integrado con la Corte Suprema de Justicia y los demás tribunales inferiores, disponiendo su competencia con carácter original o por apelación (artículos 100 y $101 \mathrm{CN}$ ).

De lo expuesto se colige que la garantía del debido proceso para el juzgamiento de delitos comunes no estaba alcanzada constitucionalmente con un derecho al recurso. La única referencia constitucional a la vía de impugnación estaba vinculada con el ejercicio del control constitucional, en cabeza de la Corte Suprema de Justicia de la Nación, pero no con el derecho de un particular al recurso contra el fallo. La vía prevista era la "apelación" del artículo 101 en su redacción original y cuya reglamentación se encuentra especialmente en los artículos 14 a 16 de la ley 48, las disposiciones procesales del Código Procesal Civil y Comercial de la Nación y en las Acordadas y doctrina del Recurso Extraordinario Federal emanada de la Corte Suprema de Justicia de la Nación.

La Corte Suprema afirmó reiteradamente que la garantía del debido proceso exige que el litigante sea oído con las formalidades legales sin depender del número de instancias que las leyes procesales puedan prever según la naturaleza de las causas (CSJN, Fallos: 126: 114; 127: 167; 155: 96; 223: 430; 231: 432; 289: 95; 298 : 252, entre otros).

\section{La exigencia convencional de doble conforme: segunda condición para penar}

La suscripción por parte de nuestro país de los Tratados Internacionales sobre Derechos Humanos como la Convención Americana sobre Derechos Humanos (en adelante CADH) y el Pacto Internacional de Derechos Civiles y Políticos (en adelante PIDCP) introdujo a la garantía del debido proceso una estructura complementaria a arraigada mediante la primera condición.

Por imperio del artículo 8.2.h. de la CADH y 14.5 del PIDCP surge una segunda condición para penar, cuya fuente reconoció jerarquía constitucional a partir de la reforma de 1994. El juicio previo ya no era condición suficiente para la aplicación de una pena. 
De la CADH y del PIDCP resulta que, si del juicio previo deriva una sentencia condenatoria, el imputado tiene derecho a la revisión del fallo. La nueva condición cobija, al igual que la primera, un único sentido entre las posibles alternativas. Ese sentido es el de la condenación penal.

Surge una nueva garantía conocida como doble instancia o doble conforme, que técnica y estructuralmente integra la garantía del debido proceso, como segunda condición.

La estructura constitucional del debido proceso penal como condición para condenar supone entonces: 1) la prohibición de pena sin juicio previo y; 2) la prohibición de agotar el juzgamiento con el juicio previo cuando deriva en un pronunciamiento condenatorio. En tal caso, el imputado debe contar con una instancia de impugnación efectiva y amplia para revisar el fallo mediante la intervención de otro tribunal(3).

Esto implica que la garantía de la doble instancia del artículo 8.2.h de la CADH y 14.5. PIDCP, instituida a favor del imputado - así lo ha reconocido la Corte Suprema (“Juri", Fallos: 329:5994; “Arce", Fallos: 320:2145)—, no conforma una protección aislada o descontextualizada. Por el contrario, a esta garantía le precede otra, la del juicio previo, que materializa el derecho a ser oído del imputado y su derecho de defensa frente a la acusación penal.

El Estado encuentra en estas garantías dos prohibiciones: a) no puede penar sin juicio previo; b) no puede vedar el acceso del imputado a otro tribunal para revisar el fallo condenatorio, con los estándares inherentes a la protección (revisión amplia, no sometida a formalidades que excedan la razonabilidad de su regulación, basada en el deber de máximo rendimiento a cargo del órgano ad quem, reconociendo los límites derivados de inmediación y de la delimitación de los agravios) (CSJN, Fallos: 328: 3399 “Casal”).

\section{Comparación entre la primera y la segunda condición}

Es frecuente que los conceptos "juicio" o "proceso" sean utilizados para referirse a estadios procesales que no integran técnicamente el fenómeno procesal. Y si bien la garantía del debido proceso conforma una institución sustantiva y amplia, el mérito de las condiciones constitucionales y convencionales para habilitar la imposición de una pena en el proceso penal no debe basarse, en mi opinión, en una simplificación de institutos del derecho procesal.

(3) La impugnación horizontal abre el debate acerca de si la garantía exige o no que el órgano jurisdiccional ad quem posea una competencia funcional jerárquicamente superior a la del a quo. 
Me detendré en uno de esos tópicos: la fase recursiva incluida en el concepto de juicio previo. El recurso, así como la instancia procedimental recursiva, no abre una nueva etapa de juzgamiento, ni completa un juicio inconcluso. La impugnación determina una fase diferente, cuya naturaleza es la revisión de una sentencia y no la sustanciación de una acusación en el marco de un debate dialéctico.

La incorrección de semejante asociación es prontamente detectada al ser confrontada con la primera condición. Porque si la fase recursiva constituye un segmento del juicio o, peor, un nuevo juicio, ninguna sentencia derivada del juicio previo propiamente dicho podría condenar. Si así ocurriese, la condena no reconocería el juicio previo sino solo un fragmento de este. En ese caso, la única pena posible de ser dictada quedaría en cabeza del máximo tribunal de justicia, que impediría la prosecución del derrotero de impugnaciones y pondría fin al juicio previo.

El equívoco se puede mostrar también desde otro lugar. Mientras el proceso se erige para sustanciar la acusación, hacer posible la defensa, recepcionar la producción de las pruebas, recibir las alegaciones y pronunciar la sentencia (ACUSACIÓN, DEFENSA, PRUEBA y SENTENCIA), el recurso propende a la revisión de desvíos o arbitrariedades en la decisión que emana del judicante, por razones de injusticia o de ilegalidad. Como advierte Rovatti (2016, pp. 113-160), la instancia recursiva carece del método dialéctico integral y por ende no puede ser considerado "juicio".

Los recursos reconocen como su antecedente a una resolución judicial y los agravios que apoyan el remedio, pero no sustancian una acusación, en su tramitación pueden prescindir (suele ser la respuesta de los Código Procesales) de la sustanciación, normalmente está vedado el derecho de proponer y producir prueba (nunca se admitirá el ejercicio amplio de este derecho) y los jueces deben limitarse al tratamiento de los agravios que fundan el recurso. Adviértase, igualmente, que, de admitirse la sustanciación plena, el derecho amplio de ofrecer pruebas y producirlas, la fase de recurso se transformaría en un segundo juicio, consecuencia inadmisible porque se menoscabaría la prohibición de múltiple persecución penal (ne bis in idem) y los principios de progresividad y preclusión inherentes a la garantía del debido proceso.

Los recursos o medios de impugnación se sujetan a reglas de admisibilidad que, en la medida que se asciende en la pirámide de competencia funcional, estrechan el pasaje limitando el derecho a la revisión. Así ocurre particularmente con los recursos de casación, extraordinarios locales y extraordinario federal. Estas restricciones, que versan tanto sobre la admisibilidad como la competencia del órgano jurisdiccional ad quem, señalan otra diferencia sustancial entre proceso e instancia impugnativa. 
La segunda condición procura corregir posibles desvíos o arbitrariedades y con esa función es captada por los Tratados Internacionales sobre Derechos Humanos. Es decir, como situaciones contra las que debe guarecerse al imputado y no a los Estados signatarios, sin perjuicio de la protección especial de las víctimas (y en este caso los deberes de los Estados) frente a delitos de lesa humanidad, crímenes de guerra y graves violaciones a los derechos humanos que, como ya he anticipado, no integran el análisis de este opúsculo.

En los procedimientos basados en las reglas de oralidad, inmediación y continuidad la prueba se reconoce íntimamente ligada con su producción, que acaece durante el juicio y aun cuando pueda documentarse mediante registros fílmicos que pueden ser consultados por el órgano de revisión, la valoración —en caso de producirse- lo será de medios documentales, sin inmediación con la fuente auténtica y quizás tampoco con el medio documental secundario (ya que se puede delegar el contacto con el registro) y sin continuidad (que importa la fractura del valor que la regla procesal guarece)(4).

La Convención Americana sobre Derechos Humanos permite la misma distinción. Para la sustanciación de una acusación se requiere tramitar un proceso ante un tribunal imparcial e independiente y con todas las garantías. Sustanciar es bilateralizar; para bilateralizar se requiere proceso. El recurso es regulado como una instancia diferente, dirigida a la revisión por el imputado de la sentencia condenatoria no firme. Ese derecho implica someter la sentencia al escrutinio de otro tribunal, calificado como "superior" (5).

Sentado que en el concepto "juicio previo" no puede incluirse el recurso ni la instancia recursiva, se tornan obligadas las consideraciones que siguen.

\section{Coherencia entre la primera y la segunda condición}

La condena requiere, para el respeto de todas las garantías analizadas, del antecedente necesario e inmediato del proceso (artículo $18 \mathrm{CN}$ ). Si como consecuencia

(4) El recurso amplio contra la sentencia y la oralidad reconocen importantísimas tensiones que ponen en crisis los fundamentos para la adopción de esta segunda regla procesal. Esta cuestión ha sido objeto de investigación en el Proyecto "Relaciones socioculturales en el proceso judicial: oralidad, escritura y revisión de sentencias", 03/J010, acreditado en la Universidad Nacional del Centro de la provincia de Buenos Aires.

(5) La expresión podría reñir con la solución adoptada por la Suprema Corte de Justicia de la provincia de Buenos Aires (Causa P 108.199, "Carrascosa, Carlos Alberto. Recurso de casación”, del 24/06/15) y por la Corte Suprema de Justicia de la Nación (CSJ 5207/2014/RH1, P., S. M. y otro s/ homicidio simple, del 26/12/2019) con cita de los precedentes Duarte (Fallos: 337:901) y Di Nunzio (Fallos: 328: 1108) al disponer la revisión horizontal. 
del juicio previo el órgano de juzgamiento absuelve, no es constitucionalmente admisible el dictado de una condena en las instancias recursivas. De manera que cuando un Tribunal de Alzada o Casación revocando una absolución dicta por primera vez la condena, infringe la garantía del debido proceso al penar sin juicio previo.

La prohibición de penar sin juicio previo determina que la absolución consecuente de un juicio válido y regular cierra definitivamente la discusión para quien ejerce la persecución penal, ya que la garantía judicial de la doble instancia se erige solo a favor del condenado y el trocamiento de una absolución en la fase revisora infringe la prohibición de penar sin juicio previo. Una condena pronunciada por un tribunal que decide la impugnación contra el fallo absolutorio no cumple la primera condición ya que la derivación del juicio previo ha sido la sentencia absolutoria.

Los instrumentos internacionales que se vienen analizando (CADH y PIDCP) no prevén la primera condición. De modo que los criterios interpretativos y estándares de la Corte IDH deben ser aplicados en el sistema interno como pautas mínimas. De este modo resulta necesario integrarlos con la primera condición que resulta del derecho constitucional argentino y opera como una tutela que incremente la protección. Por esa razón, la garantía del debido proceso resulta de la integración de condiciones cuyas fuentes son la Constitución Nacional (primera) y Pactos Internacionales de Derechos Humanos con igual jerarquía (segunda).

Voy a retomar el análisis del adjetivo previo que acompaña el sintagma constitucional y que he diferido para esta oportunidad (ver supra 3). Podría contestarse mi argumento señalándose que la primera condición constitucional no implica una fuerte y directa conexión entre juicio previo y sentencia condenatoria. De modo que el adjetivo enlazaría una mera prelación temporal, pero no una relación lógica y consecuencial. En ese caso, la expresión constitucional no eludiría la tautología. Según este razonamiento, la sentencia condenatoria no debería ser necesariamente la consecuencia directa e inmediata del juicio previo. La condición se cumpliría siempre que la sentencia condenatoria, cualquiera sea la instancia de la que procede y la distancia entre ambas, reconozca un juicio previo en algún momento del derrotero procedimental. No se me escapa que es esta la interpretación que prima en nuestros tribunales. Por ese motivo debo insistir con la demostración del equívoco.

Si el proceso constituye el eje central de la garantía de debido proceso frente al riesgo o amenaza de resultar penado (artículo $18 \mathrm{CN}$ ) o condenado (artículo 8.2.h CADH y PIDCP), la derivación de la condición de juicio previo para penar no puede ser otra que la consecuencia o resultante del debate penal.

Solo si negamos la naturaleza garante del proceso y le atribuimos la calidad de instrumento dirigido a hacer efectivo y posible la imposición de una pena, 
podríamos conceder una licencia hermenéutica y hacer de lo previo un saco roto o letra muerta, habilitando múltiples instancias y oportunidades - todas las que las leyes procesales acuerden - para acertar en el objetivo. Pero advierto que no es coherente sostener lo primero (garantía) y concluir lo segundo.

Corresponde considerar un argumento fuerte que suele invocarse a favor del recurso de la acusación (con o sin legitimado particular) frente a la decisión absolutoria. En este sentido han sido invocados los criterios de la Corte IDH.

La jurisprudencia de la Corte IDH no señala la necesidad de vinculación o fuerte relación (lógica y consecuencial) entre sentencia condenatoria y juicio. Pero hete aquí que la Corte IDH no resuelve aplicando la Constitución Nacional Argentina, sino los instrumentos internacionales a los que he hecho referencia, los cuales no contemplan la primera condición como garantías judiciales mínimas. Por consiguiente, considerar la exigencia de la primera condición en el ámbito del Sistema Interamericano de Derechos Humanos es un error.

De este análisis resulta que los criterios de la Corte IDH que señalan el deber de los Estados de habilitar un recurso amplio y sencillo contra la sentencia condenatoria, cualquiera sea la instancia de la que procede, se ciñen a la interpretación y alcance de las disposiciones convencionales, pero no reemplazan ni sustituyen las mayores protecciones que derivan de nuestra constitución.

De modo que los criterios de la Corte IDH, por ejemplo, en el precedente "Mohamed vs. Argentina" (sentencia del 23 de noviembre de 2012), no son incompatibles con la primera condición. Y, en la medida que nuestros tribunales y especialmente la Corte Suprema de Justicia de la Nación la adopten con el alcance señalado, se verá satisfecha la garantía del debido proceso con los estándares internacionales y de derecho interno.

Bidart Campos (2002) advertía sobre la necesaria interpretación que compatibilizara las posibles diferencias entre el garantismo de la jurisdicción penal internacional y la legislación interna de nuestro país, de modo que "ninguna cláusula del tratado menoscabe o minimice las garantías que la constitución contiene para la sustanciación de los procesos judiciales" (párrafo 5). Estas mismas consideraciones cuadran para la integración de los controles de constitucionalidad y convencionalidad.

\section{Estándares de la Corte IDH respecto de la segunda condición}

Como he anticipado, la Corte IDH ha delineado los estándares de la garantía de la doble instancia contemplada en el artículo 8.2.h) CADH y 14.5 PIDCP. En prieta síntesis se ha pronunciado sobre los "estándares que deben ser observados 
para asegurar la garantía del derecho de recurrir del fallo ante juez o tribunal superior" (casos "Castillo Petruzzi y otros vs. Perú"; "Herrera Ulloa vs. Costa Rica"; "Barreto Leiva $v s$. Venezuela"), señalando que es necesario que las disposiciones del artículo 8 de la CADH se observen en todo proceso (caso "Hilaire, Constantine y Benjamin y otros $v s$. Trinidad y Tobago"; caso "Tiu Tojín $v s$. Guatemala”).

En particular, ha indicado que las garantías judiciales del artículo 8 “(...) condicionan el ejercicio del ius puniendi del Estado y (...) buscan asegurar que el inculpado o imputado no sea sometido a decisiones arbitrarias, toda vez que se deben observar 'las debidas garantías' que aseguren, según el procedimiento de que se trate, el derecho al debido proceso" (caso "Barbani Duarte y otros vs. Uruguay", párr. 117).

La garantía de la doble instancia importa un ejercicio efectivo, real y sencillo -no sujeto a restricciones o limitaciones formales irrazonables-del recurso contra la decisión que constriñe y afecta la libertad y demás derechos fundamentales (Corte IDH, caso "Herrera Ulloa vs. Costa Rica"; caso "Barreto Leiva vs. Venezuela. Fondo, Reparaciones y Costas", entre otros).

Mediante sentencia del 23 de noviembre de 2012, la Corte IDH se pronunció en el caso "Mohamed $v s$. Argentina". La Corte debió considerar si la protección del artículo 8.2.h de la CADH permitía una excepción, alegada por nuestro país, cuando la condena procede de un tribunal que resuelve un recurso interpuesto contra la sentencia absolutoria.

La Corte IDH sostuvo:

(...) El artículo 8.2 de la Convención contempla la protección de garantías mínimas a favor de '[t]oda persona inculpada de delito'. En el último inciso en que expone esas garantías, cual es el h), protege el 'derecho de recurrir del fallo ante juez o tribunal superior'. La Corte entiende que el artículo 8.2 se refiere, en términos generales, a las garantías mínimas de una persona que es sometida a una investigación y proceso penal. Esas garantías mínimas deben ser protegidas dentro del contexto de las distintas etapas del proceso penal, que abarca la investigación, acusación, juzgamiento y condena (parágrafo 91).

(...) Teniendo en cuenta que las garantías judiciales buscan que quien esté incurso en un proceso no sea sometido a decisiones arbitrarias, la Corte interpreta que el derecho a recurrir del fallo no podría ser efectivo si no se garantiza respecto de todo aquél que es condenado, ya que la condena es la manifestación del ejercicio del poder punitivo del Estado. Resulta contrario al propósito de ese derecho específico que no sea garantizado frente a quien es condenado mediante una sentencia 
que revoca una decisión absolutoria. Interpretar lo contrario, implicaría dejar al condenado desprovisto de un recurso contra la condena. Se trata de una garantía del individuo frente al Estado y no solamente una guía que orienta el diseño de los sistemas de impugnación en los ordenamientos jurídicos de los Estados Partes de la Convención (parágrafo 92).

Prestigiosa doctrina ha señalado que pronunciamientos como el que anteceden demuestran que el recurso del Ministerio Público Fiscal o del querellante contra el fallo absolutorio no infringe la convención. Y aun cuando su ejercicio no se encontraría amparado por el artículo 8.2.h. CADH, que opera a favor del imputado, encontraría basamento en la garantía de tutela judicial efectiva de los artículos 8.1. y 25 de la $\mathrm{CADH}$, que amparan a toda persona, cualquiera sea su situación frente a la ley.

Se trata, en mi opinión, de una forzada conclusión. En primer lugar, por el señalamiento inicial efectuado en este acápite acerca de que los criterios de la Corte IDH no pueden aplicarse en detrimento, o con exclusión, de la mayor protección proveniente del derecho interno. En segundo término, porque la tutela judicial efectiva se satisface con el legítimo derecho de intervenir, postular, pretender y eventualmente acusar, en el juicio previo.

Hago propias las palabras de Chiara Díaz y La Rosa (2013):

(...) La 'tutela judicial efectiva' (artículos 80.1 y 25.1, CADH) expresa la obligación de los Estados de resguardar judicialmente los derechos de todas las personas, y entre ellas las víctimas, pero esto no tiene una correlación directa con un presunto 'derecho a recurrir fallos penales'; de otro modo, además, carecería de sentido que la misma Convención disponga una norma independiente que específicamente así lo establece (artículo 8o.2.h). En suma, el acusador particular tiene derecho a ser oído y sus planteos tratados ante las instancias que la ley le otorga y, en este sentido, al ser parte legitimada en un litigio penal, tiene garantizado constitucionalmente su derecho al debido proceso. Sin embargo, es discutible que tenga garantizada la revisión del fallo penal adverso, lo cual, en principio, no se encuentra establecido en la Constitución ni en los pactos (...) (p. 198).

El debido proceso o juicio es el ámbito connatural con el ejercicio de los derechos y las pretensiones que comprenden al Ministerio Público Fiscal como acusador público y eventualmente al particular damnificado o querellante como acusador privado, cuya legitimación le ha sido reconocida en función del interés 
resarcitorio y no punitivo per se(6). Si el proceso ha sido regular, si las partes han contado con todas las garantías para deducir sus pretensiones, procurar su acreditación, si han sido oídas en plena igualdad y si, finalmente, se ha dictado sentencia por un tribunal independiente e imparcial, la tutela judicial efectiva ha quedado guarecida. De lo expuesto se colige que la tutela judicial efectiva no constituye una razón correcta para admitir el recurso contra el fallo absolutorio.

No es correcto extrapolar a los casos de derecho penal común las resoluciones y criterios de la Corte IDH sobre categorías propias del Derecho Internacional sobre los Derechos Humanos cuando se ha debatido delitos de lesa humanidad, crímenes de guerra o graves violaciones a los derechos humanos. Existen sobrados ejemplos en los cuales la resolución de la Corte IDH ha versado en torno a la tutela judicial efectiva de las víctimas de tales crímenes, mediante inacción, complicidad o negligencia del Estado en el acceso de las víctimas a los tribunales.

Se ha invocado, también, como razón justificante del recurso contra el fallo absolutorio, al principio de igualdad procesal, que se lo asocia mejor al modelo bilateral de recursos. La vigencia plena de la igualdad procesal no se traduce en la bilateralidad recursiva. La igualdad procesal parte del contexto de desigualdades que, reconocidas, exigen la articulación de respuestas correctivas y en ocasiones estas correcciones se presentan como asimétricas. La igualdad procesal parte de la equivalencia de trato, audiencia e instancia, que cimentan el desarrollo del contradictorio o proceso penal. Sin embargo, concurren asimetrías que hacen posible el debido proceso, apartándose del mero procedimiento anacrónico en el que una igualdad recursiva formal y abstracta, basada en la exacta equivalencia de remedios impugnativos, colisionaría con la desigualdad real que el ciudadano posee frente al Estado, se desentendería de ideal de libertad como principio constitucional, y comprometería el equilibrio entre los principios de reserva y legalidad (artículos 18 y $19 \mathrm{CN}$ ).

Son ejemplos incontrastables de asimetrías el estado de inocencia, in dubio pro reo, favor rei, el principio de mínima intervención, la garantía a guardar silencio del imputado, la prohibición de reformatio in peius y las dos condiciones bajo análisis.

La Corte Suprema de Justicia de la Nación, en el precedente "Arce" (Fallos: 320: 2145), ha señalado:

(...) las garantías emanadas de los tratados sobre derechos humanos deben entenderse en función de la protección de los derechos esenciales del ser humano y no para beneficio de los estados contratantes. En este sentido la Corte Interamericana, cuya jurisprudencia debe servir como guía para la interpretación de esta Convención, en la medida en

(6) Este enunciado no aplica para las víctimas de delitos de lesa humanidad, crímenes de guerra y graves violaciones de derechos humanos. 
que el Estado argentino reconoció la competencia de dicho tribunal para conocer en todos los casos relativos a la interpretación y aplicación de los preceptos convencionales (confr. artículos 41, 62 y 64 de la Convención y artículo 2 ley 23.054), dispuso: los Estados (...) asumen varias obligaciones, no en relación con otros Estados, sino hacia los individuos bajo su jurisdicción (OC-2/82, 24 de septiembre de 1982, párrafo 29) (considerando 6).

(...) las partes en el proceso penal no persiguen intereses iguales. En efecto, lo que caracteriza al proceso penal es la ausencia de un permanente antagonismo, propio del proceso civil. Ello deriva del carácter público de la pretensión que persigue el Ministerio Público, la cual muchas veces puede coincidir con el interés particular del imputado, pues su función es la reconstrucción del orden jurídico alterado. Así lo ha entendido el representante de la República Argentina, doctor José María Ruda, en la discusión del Pacto Internacional de Derechos Civiles y Políticos, la ley debe conceder idénticas garantías a todos los que se encuentran en la misma situación ante los tribunales en materia criminal, los derechos del Procurador General no son iguales que los del acusado. Todos los individuos deben ser objeto de igual protección, pero no son iguales ante los tribunales, ya que las circunstancias varían en cada caso (confr. Trabajos preparatorios del Pacto de Derechos Civiles y Políticos, Naciones Unidas, Asamblea General, tercera comisión, decimocuarto período de sesiones, art. 14 de proyecto, 24 de noviembre de 1959) (considerando 10).

(...) el principio de la igualdad de todas las personas ante la ley, según la ciencia y el espíritu de nuestra Constitución, no es otra cosa que el derecho a que no se establezcan escepciones ó privilegios que escluyan a unos de lo que se concede a otros en iguales circunstancias, de donde se sigue forzosamente que la verdadera igualdad consiste en aplicar en los casos ocurrentes la ley según las diferencias constitutivas de ellos (Sic, Fallos: 16:118; 137:105; 270:374; 306:1560, entre otros) (considerando 11).

De acuerdo con lo expuesto, la igualdad procesal no configura una razón valedera para erigir un recurso contra el fallo absolutorio.

\section{Cuestiones no abordadas: la nulidad de la sentencia absolutoria y reenvío}

La extensión que en esta publicación insumiría el abordaje de la nulidad de la sentencia absolutoria, decretada por el tribunal ad quem con reenvío a la instancia 
de origen para el dictado de un nuevo pronunciamiento, hace necesario un abordaje separado. Estos casos, alcanzados por un efecto muy potente de la nulidad procesal conocido como retrogradación de la serie procesal, llevan implícita la invalidación del debate oral para hacer posible que una nueva composición del tribunal $a$ quo puede dictar la sentencia. El fenómeno presenta aspectos comunes con las abordadas en este trabajo, pero reconoce problemáticas propias derivadas de la invalidación de la sentencia y del juicio previo y su reedición.

\section{Conclusiones}

La garantía del debido proceso en materia penal reconoce dos condiciones sucesivas, coherentes y complementarias para penar. La primera surge del texto constitucional y se define con la expresión "juicio previo". El juicio previo implica que la pena solo puede ser impuesta por la sentencia que deriva en forma directa del juicio, su antecedente lógico. El adjetivo "previo" arraiga la conexión lógica y consecuencial entre proceso y sentencia condenatoria. El adjetivo señala una cualidad que particulariza la esencia del sustantivo (juicio) y que lo caracteriza más allá de la referencia meramente temporal. La segunda condición, que se presenta cuando la sentencia dictada es condenatoria, emerge de la CADH y del PIDCP y se define como doble conforme o doble instancia. La persona que ha resultado condenada tiene derecho a obtener la revisión de la decisión por un tribunal distinto al que pronunció el fallo condenatorio. La segunda condición, que ha sido material de desarrollo especial por la Corte IDH, no puede interpretarse ni aplicarse en nuestro país con independencia de la primera condición o en detrimento de esta. La mayor protección derivada del derecho interno debe integrarse incrementando los estándares mínimos previstos por los instrumentos internacionales.

Si el restado del juicio es una sentencia absolutoria y el proceso fue llevado en forma regular y sin vicios esenciales, las condiciones analizadas impiden que un órgano jurisdiccional en la instancia impugnativa revoque la absolución y dicte una condena.

La condena procedente de una instancia revisora infringe la primera condición, por no resultar la consecuencia del juicio previo sino de la fase recursiva.

\section{Bibliografía}

Alvarado Velloso, A. (2015). Lecciones de Derecho Procesal adaptadas a la legislación procesal civil y penal de la provincia de Buenos Aires por Gustavo Calvinho y Gabriel H. Di Giulio. Buenos Aires: Astrea.

Cafferata Nores, J. I. (2011). Proceso Penal y Derechos Humanos: la influencia de la normativa supranacional sobre derechos humanos de nivel constitucional en 
el proceso penal argentino, 2da. ed. 1ra. reimpresión. Buenos Aires: Editores del Puerto.

Carbone, C. A. (2018). Sentencia arbitraria que nulifica condena en caso de jurado popular estancado. LLBA 2018 (octubre), 3, versión online AR/DOC/2181/2018. Recuperado de www.informaciónlegal.com.ar [Fecha de consulta: 28/03/2020].

Chiara Díaz, C. A. y La Rosa, M. R. (2013). Derecho Procesal Penal, tomo 2. Buenos Aires: Astrea.

Di Blasio, Y. (2019). Nulidad de sentencia y ne bis in idem. Los infortunios del eterno acusado. $D P y C$ (septiembre), 13/09/2019, 256. Recuperado de www.informaciónlegal.com.ar [Fecha de consulta: 25/03/2020].

Di Giulio, G. H. (2019). Acción penal, prescripción y delitos sexuales contra niños, niñas y adolescentes. En M. H Borinsky y D. Shurjin Almenar, Temas de Derecho Penal y Procesal Penal (pp. 859-873). Buenos Aires: Erreius S.A.

Díaz Cantón, F. (2001). El cuestionamiento a la legitimidad del recurso del acusador contra la sentencia con miras a agravar la situación del imputado. Nueva Doctrina Penal, 2001/A (pp. 145-162). Buenos Aires: Editores del Puerto.

Freire, M. (2019). La impugnación del fiscal contra las sentencias definitivas. Su configuración en el diagrama recursivo bonaerense. LLBA (agosto), 1. Recuperado de www.informaciónlegal.com.ar [Fecha de consulta: 27/03/2020].

Herbel, G. A. (2013). Derecho del imputado a revisar su condena. Buenos Aires: Hammurabi.

Isola, A. E. (2005). El recurso extraordinario federal, de qué manera influye en el recurso de casación penal? Recuperado de www.saij.jus.gov.ar [Fecha de consulta: 25/03/2020].

Jauchen, E. M. (2005). Derechos del Imputado. Buenos Aires: Rubinzal Culzoni.

Maier, J. B. J. (2004). ¿Es la "inmediación" una condición de la condena penal?: un aspecto parcial de la lucha entre Inquisición vs. Composición. Jueces para la democracia, № 49, (pp. 13-20). Recuperado de www.informaciónlegal.com.ar [Fecha de consulta: 02/03/2020].

Maier, J. B. J. (2015). Derecho Procesal Penal, tomo III (Parte General. Actos procesales). Buenos Aires: Ad-Hoc.

Massuh, V. (1990). La flecha del tiempo. Buenos Aires: Emece. 
Nestares Camargo, P. (2019). Avances de los derechos de la víctima en la ley 27.372. $D P y C$ (octubre), 83. Recuperado de www.informaciónlegal.com.ar [Fecha de consulta: 26/03/2020].

Nino, C. S. (2017). Fundamentos de derecho constitucional. Análisis filosófico, jurídico y politológico de la práctica constitucional. 5ta. reimpresión. Buenos Aires: Astrea.

Pastor, D. (1997). Recurso de Casación y anulación de oficio. Nueva Doctrina Penal, 1997/B (pp. 669-684). Buenos Aires: Del Puerto.

Rovatti, P. (2016). Casación positiva "contra reo". El paradójico derecho de recurrir "condenas sin juicio". En A. E. Ledesma (Dir.) y M. Lopardo (Coord.), El debido proceso penal (pp. 113-160). Buenos Aires: Editorial Hammurabi.

Sienra Martínez, A. (2001). La Facultad del Ministerio Público de recurrir la sentencia en contra del imputado: su inconstitucionalidad. En E. S. Hendler (Comp.), Las garantías penales y procesales: enfoque histórico-comparado (pp. 175-208). Buenos Aires: Del Puerto.

Solimine, M. A. (2013). Recurso contra la condena por absolución revocada: doble instancia, ne bis in idem. Revista Jurídica La Ley (pp. 1-14), 2013-C.

Vaccaro, N. C. y Sandhagen, A. (2020). Los puntos oscuros del precedente "P., S. M... A propósito de la sentencia de la Corte Suprema sobre la revisión horizontal. RDP 2020-4. Recuperado de www.informaciónlegal.com.ar [Fecha de consulta: $26 / 03 / 2020]$.

Zarini, H. J. (1993). Análisis de la Constitución nacional. Comentario exegético, origen, reformas, concordancias y antecedentes, 3ra. ed. ampliada y actualizada. 1ra. reimpresión. Buenos Aires: Astrea.

\section{Jurisprudencia}

Corte Suprema de Justicia la Nación Argentina.

Fallos: 272: 188 ("Mattei").

Fallos: 318: 514 (“Giroldi”).

Fallos: 320: 2145 ("Arce").

Fallos: 321: 1173 ("Alvarado").

Fallos: 328: 1108 ("Di Nunzio"). 
Fallos: 328: 3399 (“Casal”).

Fallos: 329: 1447(“Olmos").

Fallos: 329: 5994 ("Juri”).

Fallos: 333: 1687 ("Sandoval”).

Fallos: 337: 901 ("Duarte”).

Corte Suprema de Justicia de la Nación, CSJ 5207/2014/RH1, "P., S. M. y otro s/ homicidio simple", 26/12/2019. Recuperado de www.csjn.gov.ar [Fecha de consulta: 26/03/2020].

Suprema Corte de Justicia de la Provincia de Buenos Aires, Causa P 108.199, "Carrascosa, Carlos Alberto. Recurso de casación", 24/06/15. Recuperado de https://juba.scba.gov.ar/VerTextoCompleto.aspx?idFallo=132502 [Fecha de consulta: $27 / 03 / 2020]$.

Corte IDH. Caso Castillo Petruzzi y otros vs. Perú. Fondo, Reparaciones y Costas. Sentencia de 30 de mayo de 1999. Serie C No 52.

Corte IDH. Caso Hilaire, Constantine y Benjamin y otros $v$ s. Trinidad y Tobago. Fondo, Reparaciones y Costas. Sentencia de 21 de junio de 2002. Serie C № 94.

Corte IDH. Caso Herrera Ulloa vs. Costa Rica. Excepciones Preliminares, Fondo, Reparaciones y Costas. Sentencia de 2 de julio de 2004. Serie C No 107.

Corte IDH. Caso Tiu Tojín vs. Guatemala. Fondo, Reparaciones y Costas. Sentencia de 26 de noviembre de 2008. Serie C No 190.

Corte IDH. Caso Barreto Leiva vs. Venezuela. Fondo, Reparaciones y Costas. Sentencia de 17 de noviembre de 2009. Serie C No 206.

Corte IDH. Caso Barbani Duarte y otros vs. Uruguay. Solicitud de Interpretación de la Sentencia de Fondo, Reparaciones y Costas. Sentencia de 26 de junio de 2012. Serie C No 243.

Corte IDH. Caso Mohamed vs. Argentina. Excepción Preliminar, Fondo, Reparaciones y Costas. Sentencia de 23 noviembre de 2012. Serie C No 255.

Fecha de recepción: 01-04-2020 Fecha de aceptación: 18-06-2020 
